\title{
Robocasting: Prediction of ink printability in solgel bioactive glass
}

\author{
Basam A. E. Ben-Arfa | Ana S. Neto | Isabel M. Miranda Salvado | Robert C. Pullar (D) | \\ José M. F. Ferreira
}

Department of Materials and Ceramic Engineering/CICECO - Aveiro Institute of Materials, University of Aveiro, Aveiro, Portugal

\section{Correspondence}

Isabel M. Miranda Salvado and Robert C. Pullar, Department of Materials and

Ceramic Engineering / CICECO - Aveiro Institute of Materials, University of Aveiro, Aveiro, Portugal.

Emails: isabelmsalvado@ua.pt; rpullar@ua.pt

\section{Funding information}

Fundação para a Ciência e a Tecnologia, Grant/Award Number: IF/00681/2015, PTDC/EPH-PAT/6281/2014, UID/CTM/ $50011 / 2013$

\begin{abstract}
Bioactive glass powders synthesized by solgel are usually porous and exhibit high specific surface areas, conferring them poor ability for scaffolds fabrication using colloidal processing approaches. The difficulties associated with colloidal processing of solgel glass have hindered so far the processing of 3-D scaffolds by robocasting. This research paper investigates the importance of calcination temperature (CT) and balls to powder ratio (BPR) used upon wet milling on the maximum achievable solid loading in aqueous media. The effects of CT, BPR, and solid loading on the flow behavior and viscoelastic properties of the suspensions/pastes were evaluated in this preliminary work. The aim is to disclose the sets of experimental variables that are most promising for the formulation of printable inks, and open the way for the future fabrication of porous scaffolds by robocasting and other 3-D additive manufacturing techniques.
\end{abstract}

\section{K E Y W O R D S}

balls to powder ratio, calcination temperature, robocasting, scaffolds, solid loading, suspension rheology

\section{1 | INTRODUCTION}

Robocasting started to be used about two decades ago as a revolutionary tool to produce complex shaped ceramic and composite components. ${ }^{1}$ The technique is based on the extrusion of a paste (ink) throughout a nozzle, and its deposition in a layer-by-layer fashion to build the final desired shape according to a CAD (computer aided design) model. The ink is made by mixing a powder with water and small percentages of processing additives, including dispersants, binders, thickening agents and coagulants, in order to obtain the desired rheological properties. A suitable ink for robocasting should steadily flow under the applied shear stress without clogging the nozzle. It should become thinner under shear (ie, have a shear thinning flow behavior) to facilitate extrusion, and then exhibit a fast recovering of the internal structure for shape retention, while offering mechanical support to the subsequent layers. ${ }^{2}$ This is to say that setting the suitable viscoelastic behavior of pastes for Robocasting is a challenging process, as it depends on many experimental factors.

The most relevant factors determining the rheological behavior of the starting suspensions include: solid loading size (PS) and particle size distributions (PSD), ${ }^{3-5}$ particle shape and density, ${ }^{6}$ and the interfacial solid/liquid interactions. ${ }^{7,8}$ Maximizing the solid loading is an important issue for minimizing the dimensional variations of the constructs during the drying and sintering steps. ${ }^{7,9}$ However, an obvious consequence of incrementing the dispersed solids volume fraction of a given powder is the increase in viscosity of the resulting suspension. ${ }^{7-14}$ Therefore, the optimal solids volume fraction has to be a balance achieved between these two desirable but incompatible features: a maximum solid loading, and a relatively low viscosity that determines the easiness of preparation, handling, and casting of the suspensions. ${ }^{8,9}$ 
Repulsive interparticle forces are required for overcoming the attractive Van der Walls forces and preparing dense and homogeneous suspensions with good flow properties for colloidal processing. ${ }^{7-13,15,16}$ Repulsive forces can be of electrostatic origin, or be created by steric hindrance of polymeric species specifically adsorbed at the surface of the particles, or be achieved by a mixed electrosteric stabilization mechanism when polyelectrolytes are used as dispersants. $^{3,15,16}$ The solid/liquid interactions can be manipulated by selecting suitable processing additives for the specific system. ${ }^{7,10}$

Particle size determines the balance between buoyancy and sedimentation trends for individual particles, as well as the apparent increase in solids volume fraction due to the hydrated surface layer thickness $(\delta)$ formed around each dispersed particle, according to Equation (1):

$$
\phi_{\mathrm{eff}}=\phi\left(1+\frac{\delta}{a}\right)^{3}
$$

where $\varphi$ and $\varphi_{\text {eff }}$ are the true and the effective solids volume fractions, and a is the real particle radius. Considering that $\delta$ depends essentially on the pair dispersion conditions/ material, and therefore can be considered independent on the particles diameter. An obvious consequence of Equation (1) is a drastic decreasing trend of the maximum achievable solids loading when processing finer and finer nanoparticles. ${ }^{17}$

The particle packing density can be greatly improved by mixing proper volume fractions of different particle sizes having adequate mean size ratios to fit the Furnas model. ${ }^{18}$ Filling the interstitial spaces left between the coarser and finer particles have a further advantage of releasing dispersion media from those interstices, which becomes available for flow, lowering the viscosity and enabling further increments in solids loading. Although significant gains can be obtained when dealing with mortars, ${ }^{18}$ coarse particles in ceramic green bodies tend to form a kind of skeletal framework that hinders densification upon sintering, annulling the advantages of using higher solid loadings and the ability to achieve high green densities. ${ }^{8}$

Hard agglomerates tend to confer poor flow properties (shear thickening behavior) to the suspensions, implying the use of low shear rate deagglomeration processes. ${ }^{19}$ The efficient destruction of hard agglomerates is of outstanding importance for improving the flow behavior of the suspensions, the homogeneity, and the sintering ability of the green bodies. The homogeneity of green bodies (small particles and pore sizes that shorten the diffusion paths), enabling full densification and sub-micrometer grain sizes and transparent ceramics to be achieved at relatively low sintering temperatures is the best proof of this concept. $^{20-22}$
It is likely that any new colloidal system requires a specific systematic approach for disclosing the experimental variables that have stronger impacts on the rheology, and the malleability of the suspensions/pastes prepared thereof. The intrinsic porosity of a solgel derived bioactive glass powder is a new critical feature, the effects of which need to be addressed. Direct ink writing of melt-quenching glasses was already studied and is reasonably well documented. ${ }^{23-28}$ To the best of the authors' knowledge, the processing of solgel glasses by robocasting was not yet investigated so far. A literature survey revealed that almost no work has been done to demonstrate the combined effects of porosity and particle/agglomerate size on the rheological properties of the suspensions prepared from solgel derived bioactive glass powders. This is particularly true in the case of fabrication of porous scaffolds by robocasting from solgel derived bioactive glass pastes. Therefore, the purpose of this study is to disclose how the changes in calcination temperature (CT), the balls to powder ratio (BPR), and in solids loading affect the flow properties of the suspensions/pastes, and the subsequent ease of additive manufacturing.

A quaternary glass composition synthesized by a unique rapid solgel process already developed by the authors ${ }^{29,30}$ was used as starting raw material for the formulation of suitable inks for robocasting. The selected composition revealed to be biocompatabile and highly bioactive, leading to the formation of a HAp layer onto the surface of the particles upon in vitro tests in SBF for periods up to 1 month. $^{31}$

\section{2 | MATERIALS AND METHODS}

\section{1 | Wet milling procedures}

A four-component $\left(\mathrm{SiO}_{2}-\mathrm{CaO}-\mathrm{Na}_{2} \mathrm{O}-\mathrm{P}_{2} \mathrm{O}_{5}\right)$ bioactive glass with a stoichiometric composition of $75 \mathrm{Si}-16 \mathrm{Ca}-5 \mathrm{Na}-4 \mathrm{P}$ (at.\%) ${ }^{29}$ was synthesized by employing a solgel route, as described previously by the authors. ${ }^{32}$ The as-dried glass was calcined in air at various temperatures $(600,800$, and $1000^{\circ} \mathrm{C}$ ), and was used as the raw material for wet ball milling experiments under different balls to powder ratio (BPR) values $(5,10$, and 15$)$ in a total of nine experimental trials. The trials, the corresponding experimental conditions used (CT and BPR) and some results obtained are summarized in Table 1 (See Results and Discussion).

The calcination was performed in three stages: $1^{\text {st }}$ stage, from room temperature (RT) to $200^{\circ} \mathrm{C}$, at the heating rate of $1^{\circ} \mathrm{C} \mathrm{min}^{-1} ; 2^{\text {nd }}$ stage, from 200 to $400^{\circ} \mathrm{C}$, at the heating rate $2^{\circ} \mathrm{C} \mathrm{min}{ }^{-1}$; and the $3^{\text {rd }}$ stage, from $400^{\circ} \mathrm{C}$ to the final calcination temperature $(\mathrm{CT})$ value $\left(600,800,1000^{\circ} \mathrm{C}\right)$, at the heating rate of $5^{\circ} \mathrm{C} \mathrm{min}^{-1}$, followed by 2 hours soaking time for all glasses to produce glass granules. 
TA B LE 1 Dependence of PSD parameters (mean size, $\left.D_{10}, D_{50}, D_{90}\right)$ and features (skewness, size span) on the history of the powders (CT, BPR)

\begin{tabular}{|c|c|c|c|c|c|c|c|c|}
\hline \multirow[b]{2}{*}{ Trial } & \multirow[b]{2}{*}{$\mathrm{CT}\left({ }^{\circ} \mathrm{C}\right)$} & \multirow[b]{2}{*}{ BPR } & \multicolumn{4}{|c|}{ Diameters $(\boldsymbol{\mu m})$} & \multirow[b]{2}{*}{ Skewness } & \multirow[b]{2}{*}{ Span } \\
\hline & & & Mean & $D_{10}$ & $D_{50}$ & $D_{90}$ & & \\
\hline E1 & 600 & 5 & 7.61 & 2.39 & 6.26 & 14.06 & 2.05 & 1.86 \\
\hline E3 & 1000 & 5 & 7.58 & 1.04 & 6.04 & 16.26 & 1.34 & 2.52 \\
\hline E4 & 600 & 10 & 5.74 & 1.57 & 4.34 & 11.10 & 2.33 & 2.19 \\
\hline E6 & 1000 & 10 & 4.51 & 0.84 & 3.44 & 9.70 & 1.52 & 2.58 \\
\hline E7 & 600 & 15 & 4.76 & 1.21 & 3.56 & 9.84 & 1.91 & 2.42 \\
\hline E8 & 800 & 15 & 3.93 & 0.87 & 2.94 & 8.15 & 2.03 & 2.47 \\
\hline E9 & 1000 & 15 & 3.74 & 0.77 & 2.86 & 7.95 & 1.65 & 2.51 \\
\hline
\end{tabular}

The glass granules were firstly dry milled for $10 \mathrm{~min}$ utes, passed through a $200 \mu \mathrm{m}$ mesh sieve, and then used as starting powders for the designed experiments. Nine wet milling operations were performed under a constant ethanol $(\mathrm{EtOH})$ to powder mass ratio $(\mathrm{EPR}=1.5)$, and fixed milling time of 1 hour. The milling was done in a S-seriesFast Mill machine, type S2-1000 (Ceramic instruments Sassuolo, Italy) under a rotational speed of $390 \mathrm{rpm}$, using a sintered alumina jar of $300 \mathrm{~cm}^{3}$ capacity (Ceramic instruments, Sassuolo, Italy) and spherical yttria-stabilized zirconia milling balls with $10 \mathrm{~mm}$ diameter (Tosoh, Tokyo, Japan). After milling, the slurry was separated from the balls and kept overnight in the oven at $60^{\circ} \mathrm{C}$ for drying. The obtained dry powders were passed through a $63 \mu \mathrm{m}$ mesh sieve to take out the large agglomerates, and their features were assessed by the characterization techniques described below.

\subsection{Characterization of the milled powders}

The average particle sizes (PS) and the particle size distributions (PSD) of the milled powders, in a volume basis, were determined using a laser diffraction particle size analyzer (Coulter LS particle size analyser, Beckman Coulter, Fullerton, CA). Measurements were done in triplicated runs.

The specific surface areas (SSA) and the sorption isotherms of the powders were measured using the BrunauerEmmett-Teller (BET method, Micrometric Gemini M-2380, Micromeritics, Norcross, GA, USA) using $\mathrm{N}_{2}$ as adsorbate. Samples were degassed at $200^{\circ} \mathrm{C}$ before the measurment.

Zeta-potential measurements were performed in both the acidic and the alkaline regions at several $\mathrm{pH}$ values to evaluate particles' surface charges for all the nine trials, using a Malvern Zeta sizer Nano ZS (Malvern Instruments,
Malvern, UK). The measurement was carried out after dispersing the powders in a background $10^{-3} \mathrm{~mol} \mathrm{~L}{ }^{-1} \mathrm{KCl}$ electrolyte solution under sonication for $\sim 10$ minutes, and gradually shifting the $\mathrm{pH}$ into both acidic and basic conditions by using $\mathrm{HCl}$ and $\mathrm{NaOH}$, respectively.

\section{3 | Suspension preparation}

For studying the rheological and printability behaviors of the inks, several suspensions containing different solid loadings between (25-45 vol.\%) were prepared from the powder samples reported in Table 1 . The powders were dispersed in deionized water in the presence of $1.1 \mathrm{wt} \%$ carboxymethyl cellulose (CMC) $\left(\mathrm{M}_{\mathrm{w}}=250\right.$ 000, Lamberti Iberia s.a.u., Castellón, Spain) as a multifunctional processing additive (dispersant, binder, and gelation agent). ${ }^{28}$ The powders were gradually added in small dosages to the dispersing solution by mixing in a planetary centrifugal mixer (ARE-250, Thinky Corp., Tokyo, Japan) to ensure homogeneous suspensions were obtained.

\section{4 | Rheological characterization of suspensions and pastes}

The rheological properties of the suspensions and pastes were assessed using a Kinexus Pro $^{+}$Rheometer (Malvern Instruments). The viscometry mode was used to measure the apparent viscosity of the tested samples, using the cone $(4 \% 40 \mathrm{~mm})$ and plate sensor system with a $150 \mu \mathrm{m}$ gap size. The viscoelastic properties of the pastes were assessed using the oscillatory mode of the rheometer equipped with plate \& plate sensor $(20 \mathrm{~mm})$, with $1 \mathrm{~mm}$ gap size. In all rheological measurements, a metal ring with deionized water as solvent trap was used to prevent water evaporation from the samples while testing. 


\section{3 | RESULTS AND DISCUSSION}

\subsection{Influence of BPR and CT on the relevant features of powders}

\subsection{1 | Particle size (PS), size span (SS) \& particle size distribution (PSD)}

The effects of the thermal history (CT) and wet ball milling conditions (BPR) on the experimental data related with PSD (mean size, $D_{10}, D_{50}, D_{90}$, skewness, size span) are disclosed in Table 1. The following general tendencies can clearly be observed from Table 1: the skewness decreases with increasing CT, while the size span shows the opposite trend, in agreement with data plotted in Figure 1. Figure $1 \mathrm{~A}$ shows the dependence of the mean size profiles as a function of CT for three values of BPR. At BPR $=5$, the mean particle size slightly increases with increasing CT from 600 to $800^{\circ} \mathrm{C}$, to be followed by an opposite trend with a further rise in $\mathrm{CT}$ to $1000^{\circ} \mathrm{C}$. Similar, but continuous, reduction trends of the mean particle sizes can be observed at both $\mathrm{BPR}=10$ and $\mathrm{BPR}=15$ with increasing CT. However, the most accentuated mean particle size reduction is obtained at $\mathrm{BPR}=15$. Figure $1 \mathrm{~B}$ shows the width of PSD, which can be represented by the size span $(S S)$ according to the following formula ${ }^{33}$ :

$$
S S=\frac{D_{90}-D_{10}}{D_{50}}
$$

In Equation (2), the parameters $D_{90}, D_{50}$, and $D_{10}$ stand for equivalent particle diameters below which there are percentages of $90 \%, 50 \%$, and $10 \%$ of the overall distribution. From these results it can be concluded that BPR has a significant effect on SS for the powders calcined at $600^{\circ} \mathrm{C}$ and milled at $\mathrm{BPR}=5$. The differences in SS are mitigated when increasing BPR to $10-15$, and become negligible for powders calcined at $800-1000^{\circ} \mathrm{C}$. These results show that mean PS and SS can be manipulated by changing CT and/ or BPR.

Considering the overall PSD of a milled powder as comprising small, intermediate, and large size ranges, its mathematical description is likely to be suitably achieved by using a multiparameter Weibull distribution, which is governed by a generic formula:

$$
\begin{aligned}
f= & f_{1,0}\left(\frac{k_{1}}{\lambda_{1,0}}\right)\left(\frac{D_{i}}{\lambda_{1,0}}\right)^{k_{1}-1} \exp \left[-\left(\frac{D_{i}}{\lambda_{1,0}}\right)^{k_{1}}\right] \\
& +f_{2,0}\left(\frac{k_{2}}{\lambda_{2,0}}\right)\left(\frac{D_{i}}{\lambda_{2,0}}\right)^{k_{2}-1} \exp \left[-\left(\frac{D_{i}}{\lambda_{2,0}}\right)^{k_{2}}\right] \\
& +f_{3,0}\left(\frac{k_{3}}{\lambda_{3,0}}\right)\left(\frac{D_{i}}{\lambda_{3,0}}\right)^{k_{3}-1} \exp \left[-\left(\frac{D_{i}}{\lambda_{3,0}}\right)^{k_{3}}\right]
\end{aligned}
$$

In this Weibull distribution, $D_{i}$ is the differential diameter, $f_{j, 0}$ denotes the relative contribution of component $j$ to the overall PSD, with $\mathrm{j}$ within the range of $1-3 . \lambda_{j, 0}$ is the mean size of the specific distribution component, and $k_{j}$ is its Weibull parameter. The calculated particle volume distribution curves for each size range component of each experimental PSD curve are shown in Figure 2. The definitions of E1-9 are shown in Table 1.

\subsection{2 | Specific surface area and pore volume}

Figure 3 reports on the dependence of BET-specific surface area (SSA) and pore volume (PV) on the calcination temperature and of the balls to powder ratio used in wet ball milling. At $600^{\circ} \mathrm{C}$, the SSA and PV vary between $\sim 100$ $130 \mathrm{~m}^{2} \mathrm{~g}^{-1}$ and $0.34-0.48 \mathrm{~cm}^{3} \mathrm{~g}^{-1}$, respectively, with the lowest values being measured for the highest $\mathrm{BPR}=15$, and the mid values being registered for the intermediate $\mathrm{BPR}=10$. With increasing CT, both SSA and PV drastically decrease, and tend to be practically overlapped for all BPR values tested. These data show that: (a) BPR exerts a
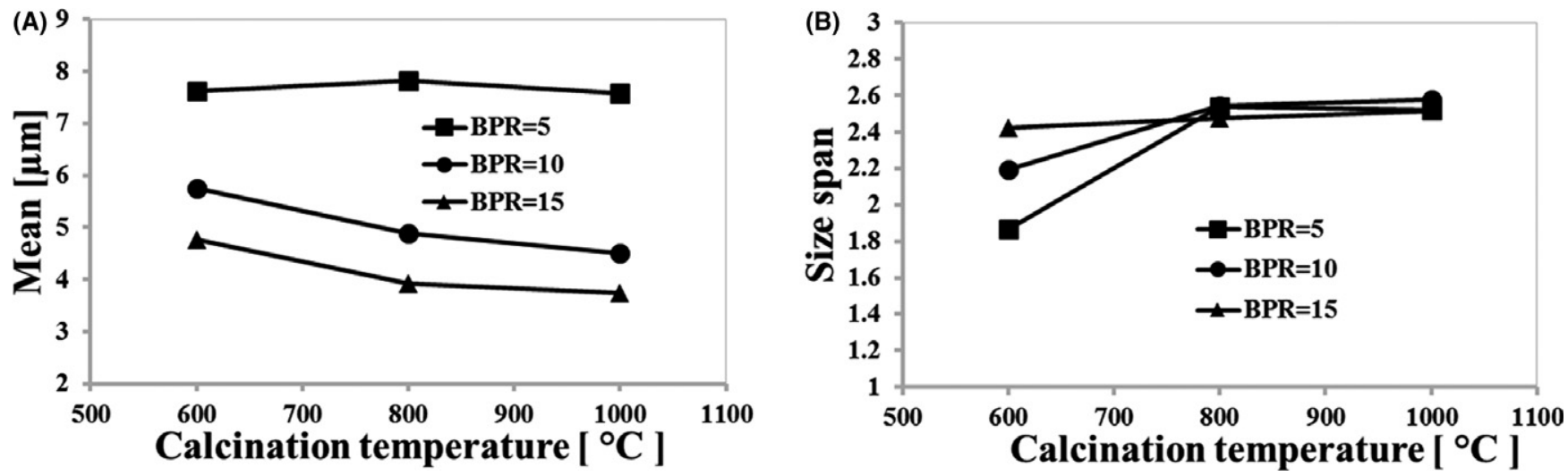

FIGURE 1 Effects of CT and BPR on the PSD features after wet milling for $1 \mathrm{~h}$ under a constant EtOH to powder mass ratio (EPR $=1.5$ ): A, mean particle size; B, particle size span 

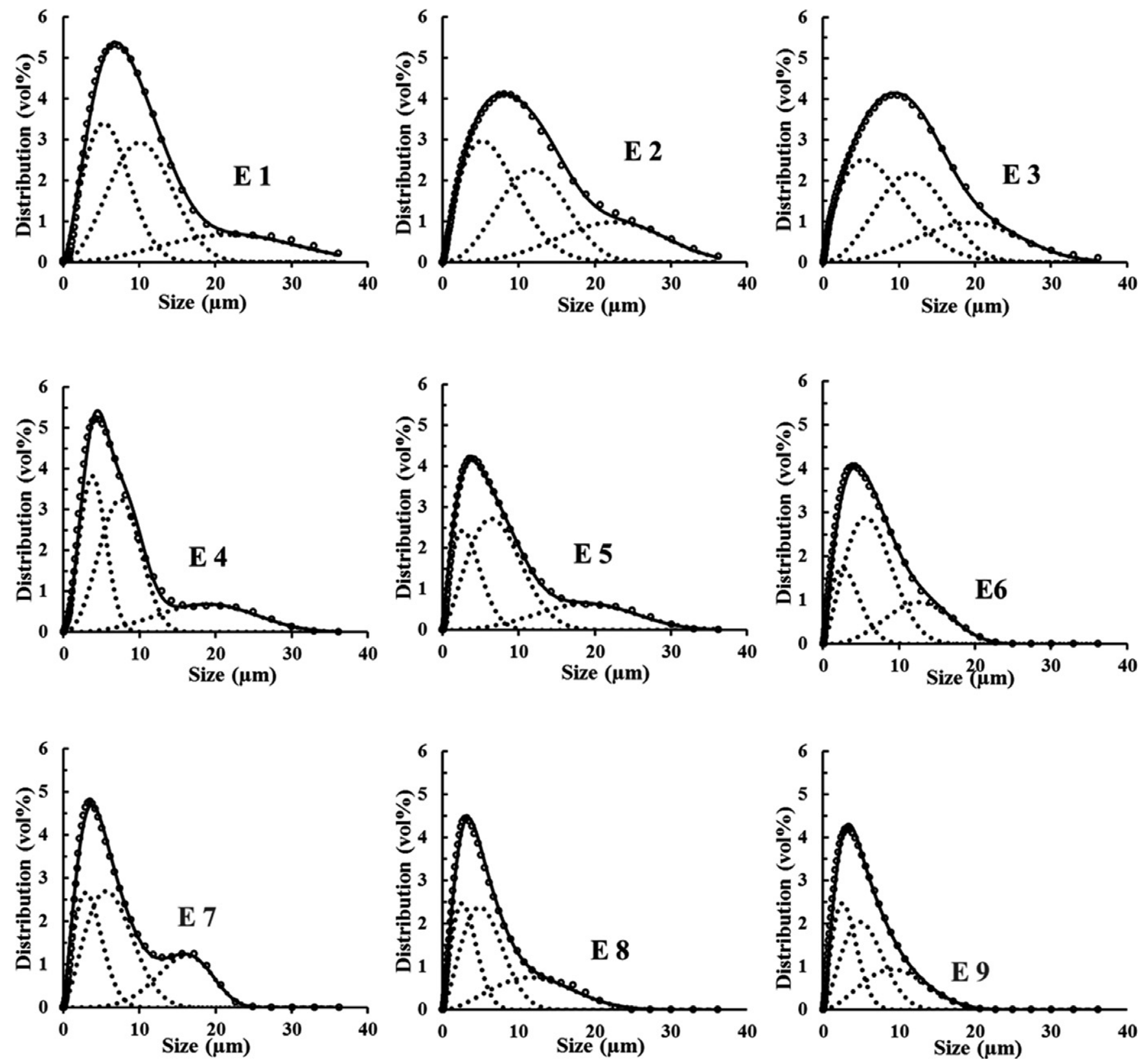

F I G U RE 2 Experimental (thick solid line) and modelled volume particle size distributions (PSD) and their Weibull deconvolutions represented by the three dotted contribution curves

secondary role in determining both SSA and PV features, but only at $600^{\circ} \mathrm{C}$, becoming completely irrelevant as calcination temperature further increases to $800-1000^{\circ} \mathrm{C}$; (b) Accordingly, CT is the main factor affecting both SSA and PV, as shown in Figure 3A,B, respectively.

With increasing CT, the smaller pores will be the first to be eliminated, being the main contributors for an overall decrease of pore volume fraction. The mechanical stresses applied upon milling tend to gradually destroy such porous structures, which is expected to break down preferentially through the larger pores. Accordingly, there is a good consistency between the concomitant decreases observed in PV (Figure 3B) and mean diameters in (Table 1).
Oppositely, the observed decrease in SSA with increasing BPR, which is accompanied by a clear particle size reduction trend (Table 1) seems counterintuitive, as milling is expected to expose new surfaces where adsorption should take place. This counterintuitive observation suggests that nitrogen condensation has already occurred in some pores with smaller radii at the maximum $\mathrm{P} / \mathrm{P}_{0}=0.35$ used. In such a condition, the total apparent amount of "adsorbate" will somewhat exceed the required amount for a monolayer formation, leading to an overestimation of the SSA. As the porous structure is gradually destroyed upon milling, some of the smaller pores become exposed, and nitrogen condensation cannot occur within such partially destroyed pores. 

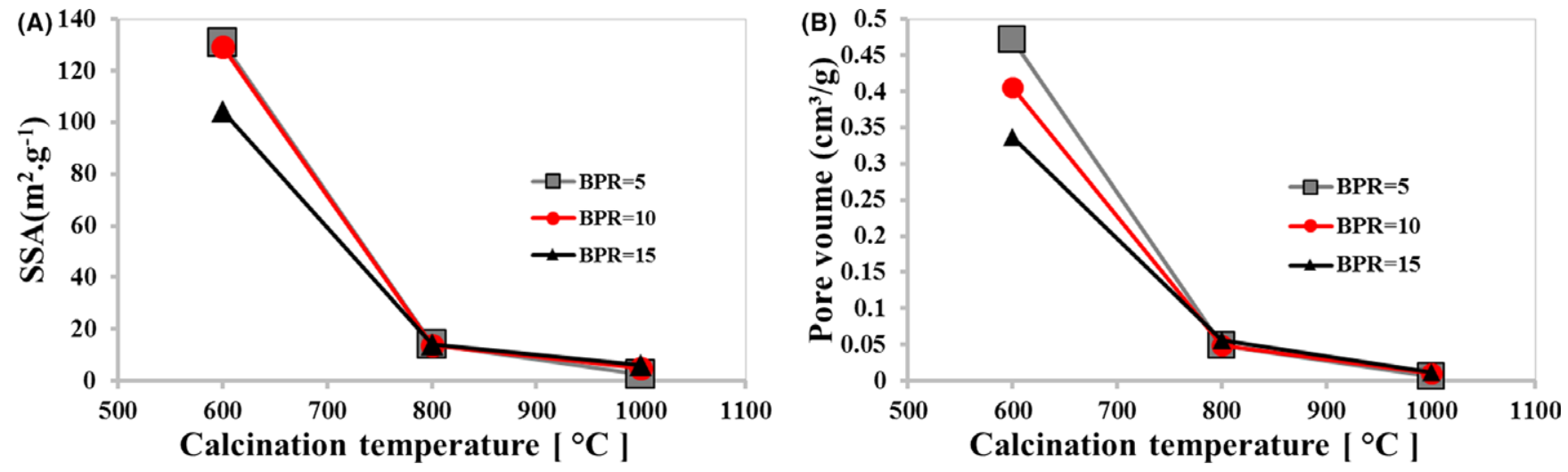

FIGURE 3 Effects of CT and BPR on the microstructural features of the powders after wet milling for $1 \mathrm{~h}$ under a constant EPR $=1.5$ and different values of BPR: A, Specific surface area; B, Pore volume. [Color figure can be viewed at wileyonlinelibrary.com]

These pores will not account anymore for the excess of nitrogen apparently adsorbed, which is translated into a lower apparent observed SSA. In other words, the values of SSA measured for the more extensively milled powders $(\mathrm{BPR}=10-15)$ calcined at $600^{\circ} \mathrm{C}$ (Figure $\left.3 \mathrm{~A}\right)$ should be more realistic than those registered for the same powder milled under $\mathrm{BPR}=5$. Moreover, the apparent reductions in SSA (Figure 3A) with decreasing mean particle sizes (Figure 1 and Table 1) observed for the powder calcined at $600^{\circ} \mathrm{C}$ suggest that the incremental adsorption by the newly created surfaces upon milling is much less relevant that the decrease in nitrogen condensation within the smaller pores, explaining the counter intuitiveness of the results obtained.

The elimination of the smaller pores with further increasing of $\mathrm{CT}$ to $800-1000^{\circ} \mathrm{C}$ offsets the nitrogen pore condensation problem. As a matter of fact, there was a tremendous reduction in SSA to $\sim 18 \mathrm{~m}^{2} \mathrm{~g}^{-1}$ with CT changing from 600 to $800^{\circ} \mathrm{C}$, with further decreases to about one half of that for $\mathrm{CT}=1000^{\circ} \mathrm{C}$ (Figure 3A). A similar tendency was observed for PV as a function of CT (Figure 3B).

\subsection{3 | Zeta potential $(\zeta)$}

Zeta potential $(\zeta)$ is used to assess the interaction forces among the particles. A value of zeta potential higher than $\pm 30 \mathrm{mV}$ is often considered to be sufficient for obtaining stable suspension. ${ }^{34,35}$ Although measurements have been made for powders samples derived from the nine trials, only data corresponding to different CTs $(600,800$, and $\left.1000^{\circ} \mathrm{C}\right)$ and milled under the two extreme BPR values (5, 15) will be reported here. Figure 4 plots the zeta potential $\zeta$ results gathered over a broad $\mathrm{pH}$ range for the selected powders (E1-3 and E7-9). It can be seen that all the samples exhibit acidic isoelectric points converging to $\mathrm{pH} \sim 2$ $\left(\mathrm{pH}_{\text {iso }} \sim 2\right)$, which are similar to that reported for silica. ${ }^{36}$ This is particularly true for the samples calcined at the

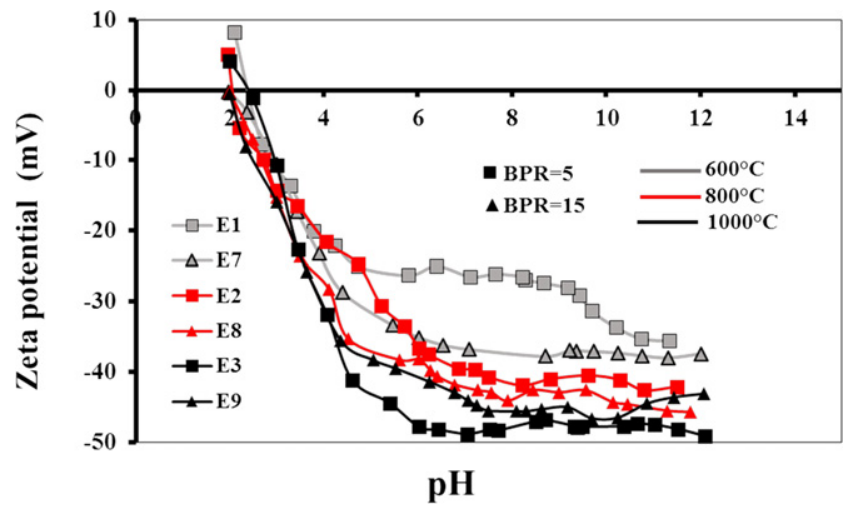

FIGURE 4 Effects of calcination temperature (CT) and of BPR on the zeta potential of the bioactive glass particles. $600^{\circ} \mathrm{C}$; (grey line), $800^{\circ} \mathrm{C}$; (red line), $1000^{\circ} \mathrm{C}$ (black line) [Color figure can be viewed at wileyonlinelibrary.com]

higher temperatures $\left(800,1000^{\circ} \mathrm{C}\right)$. With $\mathrm{pH}$ increasing, the $\zeta$ values become gradually more negative, with absolute values reaching approximate zeta potentials plateaux of 35$50 \mathrm{mV}$ within the $\mathrm{pH}$ range from 6-12.

It is clear that the negative polarity of the particles' surface becomes gradually better defined as CT increases, leading to higher absolute $\zeta$ values. Accordingly, the most and the least negative $\zeta$ values are observed for $\mathrm{CT}=$ $1000^{\circ} \mathrm{C}$ and $\mathrm{CT}=600^{\circ} \mathrm{C}$, with intermediate values being registered at $\mathrm{CT}=800^{\circ} \mathrm{C}$. Therefore, a higher $\mathrm{CT}$ is expected to favor electrostatic stabilization. ${ }^{37}$ The powder treated at $600^{\circ} \mathrm{C}$ exhibits a more porous structure, as seen from (Figure 3), and is prone to undergo a more extensive surface hydration process. With increasing $\mathrm{CT}$, the tendency for surface hydration decreases, leading to higher $\zeta$ values. The $\zeta$ profiles obtained are in good harmony with the results acquired above for both mean particle size (Figure 1A) and pore volumes (Figure 3B).

The BPR has a much more secondary role in determining interfacial solid/liquid interactions, meaning that zeta 
potential is essentially dependent on the surface polarity. ${ }^{38}$ Despite this, particle size is likely to somewhat affect the electrophoretic mobility, as gravity lends a vertical component to the motion that becomes more significant for large particles. The observed dependence of $\zeta$ on particle size is in a good agreement with the results for a range of different particle types found by Liu et $\mathrm{al}^{39} \mathrm{Kazi}$ et $\mathrm{al}^{34}$ and Lelievre et al. ${ }^{40}$ Oppositely, it contrasts with the results reported by Vasconcellos et $\mathrm{al}^{41}$ for carbon black particles, who did not find any dependency between particle size and $\zeta$.

\section{2 | Influence of the powders' features and solid loading on the rheological properties of the suspensions}

All the relevant features of the powders $\left(\zeta\right.$ potential, ${ }^{3}$ particle size and PSD profiles, ${ }^{8-13}$ porous structure, ${ }^{38}$ etc.), influence their dispersing ability. Higher values of $\zeta$ potential lead to stronger electrostatic forces among the particles. They start feeling the presence of other neighboring particles at larger distances due to the consequent increment in their apparent size, as established by Equation (1). This explains why the electrostatic stabilization mechanism often limits the maximum solids loading, in comparison to steric or electrosteric stabilization mechanisms. ${ }^{3}$

Porous particles derived from the powder calcined at $600^{\circ} \mathrm{C}$ absorb a portion of the dispersion liquid, which is no longer available to contribute to flowing. Moreover, such particles are more reactive toward water and develop lower absolute $\zeta$ potential values (Figure 4 ). The changes in the overall powder features with increasing $\mathrm{CT}$ tend to favor an aqueous dispersion. The maximum achievable solid loadings with the powders derived from the nine experiments are reported in (Figure 5). From the considerations above, it is not surprising the lower values of maximum solid loadings (25 vol.\%) are obtained for the lowest CT. Increasing the $\mathrm{CT}$ to $800-1000^{\circ} \mathrm{C}$ enables significant increments in solid volume fractions. On the other hand,

\section{Maximum solid loading \%}

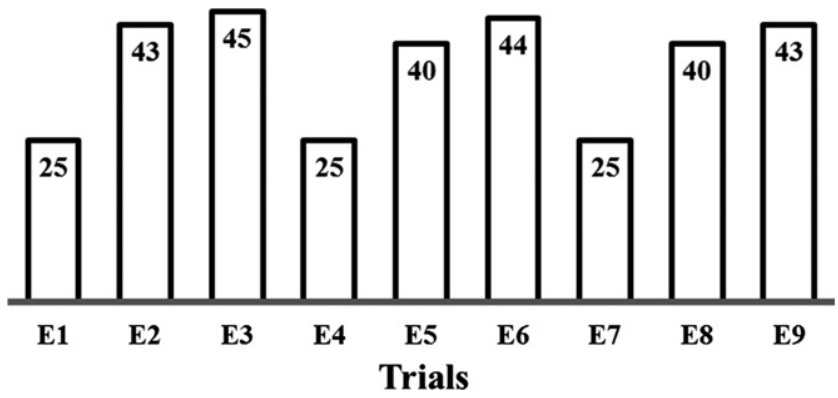

F I G URE 5 Maximum achievable solid volume fractions with the powders derived from the nine experiments the maximum achievable solid loadings show an almost negligible dependence on the BPR (and the associated PSD features reported in Figure 2 and Table 1).

\subsubsection{Apparent viscosity}

The flow properties of the suspensions were assessed in the ratational mode. The apparent viscosity curves versus shear rate of the bioactive glass slurries are displayed in Figure 6. The comparison of the flow behavior of suspensions prepared from all the powders could only be performed at 25 vol.\% solid loading, the maximum achievable for the powder heat treated at $600^{\circ} \mathrm{C}$. The flow curves displayed in Figure 6A exhibit the following interesting features: (a) an initial increase in apparent viscosity at the lowest shear rates up to a maximum point, or plateau. This is often called Zero-Shear-Viscosity (ZSV, or $\eta_{0}$ ), being commonly observed in gelled systems exhibiting yield stress; (b) a branch of decreasing viscosity along the remaining shear rate range. This shear thinning behavior is an essential requirement for extrusion, especially through fine nozzles.
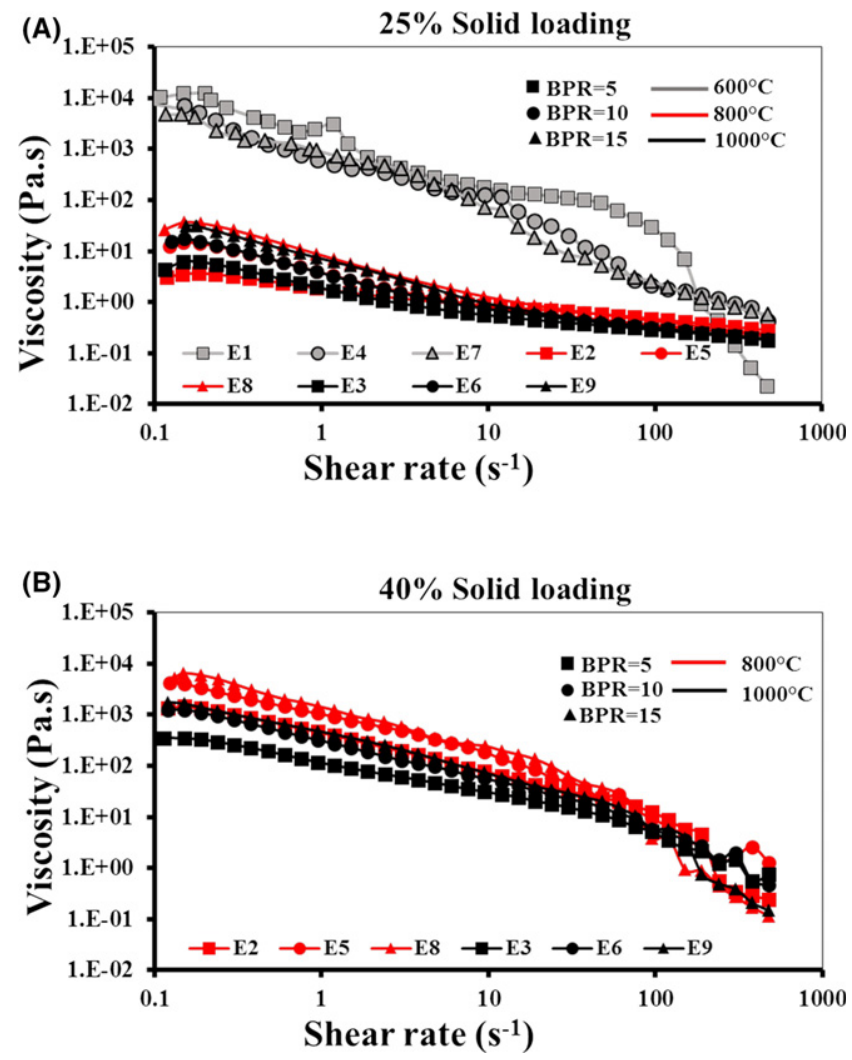

FIGURE 6 Effects of CT and BPR on the apparent viscosity as a function of shear rate at different solid loadings: A, 25 vol.\%; B, 40 vol.\%.[Color figure can be viewed at wileyonlinelibrary.com] 
The flow curves could be roughly divided into two sets depending on $\mathrm{CT}$ : one at $600^{\circ} \mathrm{C}$, and the other at 800 $1000^{\circ} \mathrm{C}$. The curves of the first set are more irregular, and the apparent viscosity levels are about three orders of magnitude higher in comparison to the other systems, especially up to $\sim 100 \mathrm{~s}^{-1}$. The BPR has a less notiable effect on the flow properties in comparison to CT. However, there is a clear general trend, also visible in Figure 6B, for the apparent viscosity to increase with particle size reduction, as expected. The increase of $\mathrm{CT}$ to $1000^{\circ} \mathrm{C}$ resulted in slightly lower apparent viscosity in comparison to systems derived from powders calcined at $800^{\circ} \mathrm{C}$. This can be attributed to a further decrease of pore size and pore volume fraction (Figure 3), and to an increase of $\zeta$ potential (Figure 4) associated with a less hydrated particle surface. ${ }^{42}$ The associated changes in PS and PSD are also likely to account for the flow properties. ${ }^{43}$ Although the flow curves for $\mathrm{CT}=600^{\circ} \mathrm{C}$ at 25 vol. $\%$ solid loading in Figure 6A exhibit similar, or even slightly higher, levels of apparent viscosity than those with $\mathrm{CT}=800-1000^{\circ} \mathrm{C}$ at 40 vol. $\%$ loading shown in Figure 6B, and printability is also likely under those conditions, the low solids loading (25 vol.\%) of the first case would imply a greater degree of shrinkage upon the drying and sintering steps. In this regard, the increases in both CT and BPR were revealed to be crucial for achieving a higher solid loadings favoring the formulation of more promising inks for robocasting.

\subsection{2 | Viscoelastic properties}

The viscoelastic properties of the formulated inks were assessed by rheological measurements under the oscillatory mode. Figure 7A-C displays the elastic modulus $\left(\mathrm{G}^{\prime}\right)$ as a function of complex shear stress for sytems containing 25 and 40 vol.\% solids. In Figure 7A it can be seen that sufficiently high $\mathrm{G}^{\prime}$ values for printing $\left(\mathrm{G}^{\prime} \sim 1 \mathrm{MPa}\right)$ could be achieved for pastes with 25 vol.\% loading derived from the powder calcined at $600^{\circ} \mathrm{C}$ and ball milled under BPR of 510 (E1 and E4). Further increasing of BPR to 15 caused a drop in $G^{\prime}$ of about one order of magnitude, suggesting that the fluidification effect of the liquid released from the smaller pores that have been more extensively destroyed upon milling overcame the thickening effect expected from the reduction in PS. Furthermore, the pastes (inks) derived from the powder calcined at $600^{\circ} \mathrm{C}$ exhibit continuous linear viscoelastic regions (LVR) that extend beyond $100 \mathrm{~Pa}$. The extensive LVR combined with the high values of $\mathrm{G}^{\prime}$ suggest that these pastes are promising for printing and shape retention. ${ }^{28,44}$ Oppositely, the pastes containing $25 \mathrm{vol} \%$ powder calcined at higher temperatures (800$1000^{\circ} \mathrm{C}$ ) exhibit extremely low $\mathrm{G}^{\prime}$ values, and show a much narrower LVR that forbids easy printability.
The increase of solid loading to 40 vol.\% (Figure 7B) enabled us to obtain pastes from the finer powders (BPR = 10 and $\mathrm{BPR}=15$ ) with promising viscoelastic properties for printing, especially in the case of the powder calcined at $800^{\circ} \mathrm{C}$ (E5 and E8). Such viscoelastic properties are similar to those of the pastes containing $25 \mathrm{vol} \%$ of the powder calcined at $600^{\circ} \mathrm{C}$ (Figure 7A). The system prepared from the coarser powder $(B P R=5)$ is insufficiently stiff
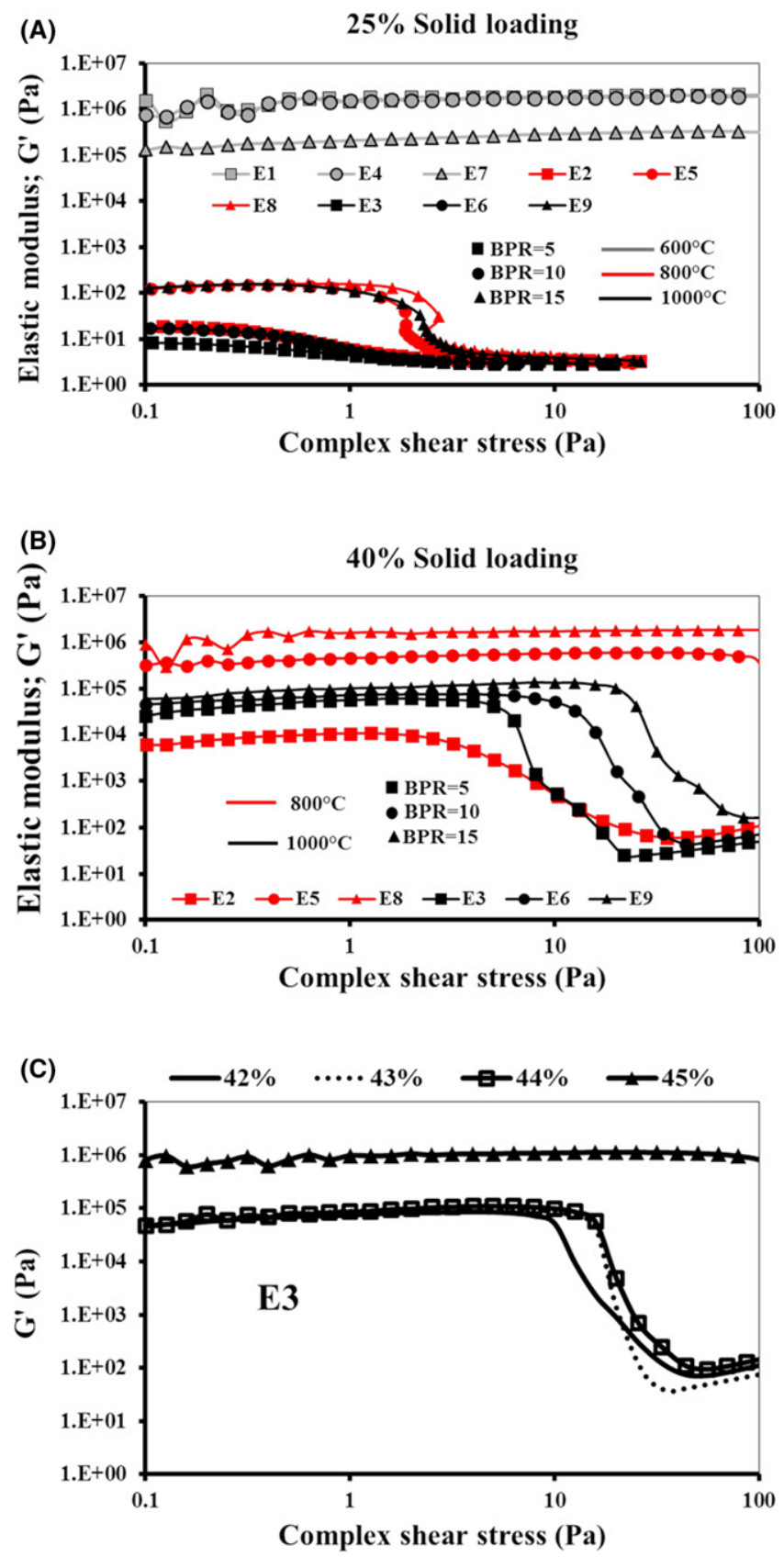

F I G URE 7 Effects of CT and BPR on the Elastic modulus $\left(\mathrm{G}^{\prime}\right)$ and the extent of LVR (linear viscoelastic regions) as a function of complex shear stress at different solid loadings: A, 25 vol.\%; B, 40 vol.\%; C, 42-45 vol.\% of E3 powder. [Color figure can be viewed at wileyonlinelibrary.com] 


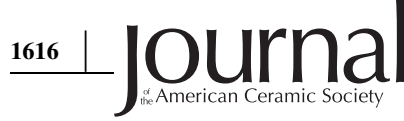

for printing. With a further increase in $\mathrm{CT}$ to $1000^{\circ} \mathrm{C}$, the pastes became even less stiff, resulting in noticeable decreases in the $\mathrm{G}^{\prime}$ magnitude and in the extent of LVR (Figure 7B). These features show a clear gradual decresing trend when moving from $\mathrm{BPR}=15$ to $\mathrm{BPR}=5$, with the last one being too soft and hardly printable.

Considering the lesser thickening effect caused by the highest $\mathrm{CT}$ and the coarser particle size $(\mathrm{BPR}=5)$; and the decreasing shrinkage undergone by structures deposited from pastes with increasing solids loading, the powder derived from experiment E3 was further explored in an attempt to maximize the solids volume fraction. The curves displayed in Figure 7C show that a solids loading of 45 vol.\% is required to achieve a $\mathrm{G}^{\prime} \sim 1 \mathrm{MPa}$, which also resulted in a long $\mathrm{LVR}$, conferring to the resulting paste a good printing potential. Further, with this E3 powder, the solids loading becomes a very critical parameter, as a small variation from 45 to 44 vol.\% caused a significant decrease in $\mathrm{G}^{\prime}$ greater that one order of magnitude, and a narrowing of the LVR to about one-fifth $(\sim 20 \mathrm{~Pa})$. Such trends become exacerbated with further decreases in the solids loading, compromising the printing ability of the pastes. Therefore, although 45 vol.\% of the powder derived from the highest CT and the lowest value of BPR (E3) enables the highest achievable solid loading among all the experiments, the printable window, in terms of other processing conditions, becomes too narrow. Playing with PSD, namely further reducing PS, is likely to give more room for optimal processing conditions.

\section{CONCLUSIONS}

Nine suspensions were prepared from high silica bioactive glass to assess their potential as inks for robocasting. The results presented and discussed above enable us to draw the following conclusions:

1. The CT negatively affects the porosity fraction and the SSA, and tends to extend the span of PSD, while the reduction in mean particle size is particularly favored by the increase in BPR.

2. The surface polarity (charge density) of the high silica bioactive glass particles was shown to depend essentially on the heat treatment temperature, gradually increasing when CT increased from $600-1000^{\circ} \mathrm{C}$. The BPR was revealed to exert only a secondary effect through its small influence on particle size.

3. The apparent viscosity, the elastic modulus, and the extent of LVR are strongly dictated by a set of interdependent factors determined by the CT, BPR, PS, PSD, and solids loading. For a given CT, the viscoelasticity is enhanced by increasing the solid loading and decreasing the mean particle size. The values of elastic modulus within the range of $10^{5}$. $10^{6} \mathrm{~Pa}$, combined with extensive of LVR with shear stress values to over $100 \mathrm{~Pa}$ measured for a number of inks, enable us to predict good printing ability. Such promising rheological properties can be obtained at a solid loading as low as $25 \mathrm{vol} \%$ for $\mathrm{CT}=600^{\circ}$ C. However, considering the benefits of higher solid loadings in terms of dimenssional control along the entire process, similar viscoelestic properties can be achieved at solid loading $>40$ vol. $\%$ by suitably adjusting all the relevant process variables, especially for $\mathrm{CT}=800^{\circ} \mathrm{C}$ and $\mathrm{BPR}=10-15$.

\section{ACKNOWLEDGMENTS}

R.C. Pullar wishes to thank the FCT Grant IF/00681/2015 for supporting this work. B. A. E. Ben-Arfa thanks FCT grant BIONANOSCULP PTDC/EPH-PAT/6281/2014 for supporting him during this work. This work was developed in the scope of the project CICECO-Aveiro Institute of Materials (Ref. FCT UID/CTM/50011/2013), financed by national funds through the FCT/MEC and when applicable co-financed by FEDER under the PT2020 Partnership Agreement.

\section{ORCID}

Robert C. Pullar iD http://orcid.org/0000-0001-6844-4482

José M. F. Ferreira iD http://orcid.org/0000-0002-42666092

\section{REFERENCES}

1. Cesarano J III. A review of robocasting technology. MRS Proc. 1998;542:133-9.

2. Eqtesadi S, Motealleh A, Miranda P, Pajares A, Lemos A, Ferreira JMF. Robocasting of 45S5 bioactive glass scaffolds for bone tissue engineering. J Eur Ceram Soc. 2014;34:107-18.

3. Tarì G, Ferreira JMF, Fonseca AT, Lyckfeldt O. Influence of particle size distribution on colloidal processing of alumina. J Eur Ceram Soc. 1998;18:249-53.

4. Olhero SM, Ferreira JMF. Influence of particle size distribution on rheology and particle packing of silica-based suspensions. Powder Technol. 2004;139:69-75.

5. Tarì G, Ferreira JMF, Fonseca AT. Influence of particle size and particle size distribution on drying-shrinkage behaviour of alumina slip cast bodies. Ceram Int. 1999;25:577-80.

6. Milewski JV. Efficient use of whiskers in the reiforcement of ceramics. Adv Ceram Mater. 1986;1:36-41.

7. Tarì G, Ferreira JMF, Lyckfeldt O. Influence of the stabilising mechanism and solid loading on slip casting of alumina. J Eur Ceram Soc. 1998;18:479-86.

8. Kaushal A, Olhero SM, Ferreira JMF. Lead-free $0.5 \mathrm{Ba}$ ( $\mathrm{Zr} 0.2 \mathrm{Ti0}$.8)O3-0.5(Ba0.7Ca0.3) $\mathrm{TiO} 3$ powder surface treated 
against hydrolysis - a key for a successful aqueous processing. J Mater Chem C. 2013;1:4846-53.

9. Tari G, Olhero SM, Ferreira JMF. Drying induced forming from highly concentrated alumina slips. Ceram Trans. 2001;112:483-8.

10. Tarì G, Ferreira JMF. Influence of solid loading on drying-shrinkage behaviour of slip cast bodies. $J$ Eur Ceram Soc. 1998;18:487-93.

11. Ferreira JMF, Diz HMM. Effect of solids loading on slip-casting performance of silicon carbide slurries. J Am Ceram Soc. 2004;82:1993-2000.

12. Yuan Z, Zhang Y, Zhou Y, Dong S. Effect of solid loading on properties of reaction bonded silicon carbide ceramics by gelcasting. RSC Adv. 2014;4:50386-92.

13. Setz LFG, Koshimizu L, de Mello-Castanho SRH, Morelli MR. Rheological analysis of ceramics suspensions with high solids loading. Mater Sci Forum. 2012;727-728: 646-51.

14. Kyrpal R, Dulina I, Ragulya A. Effect of BaTiO3 nanopowder concentration on rheological behaviour of ceramic inkjet inks. J Phys Conf Ser. 2015;602:012036.

15. Velamakanni BV, Lange FF. Effect of interparticle potentials and sedimentation on particle packing density of bimodal particle distributions during pressure filtration. $\mathrm{J}$ Am Ceram Soc. 1991;74:166-72.

16. Pugh RJ, Bergstrom L. Surface and colloid chemistry in advanced ceramic processing. Surfactant Science Series. Vol. 51. New York, NY: Marcel Dekker; 1994.

17. Nguyen CT, Desgranges F, Roy G, Galanis N, Maré T, Boucher $\mathrm{S}$, et al. Temperature and particle-size dependent viscosity data for water-based nanofluids - Hysteresis phenomenon. Int $\mathrm{J}$ Heat Fluid Flow. 2007;28:1492-506.

18. Furnas C. The relation between specific volume, voids and size composition in systems of broken solids of mixed sizes. Report of investigations (United States. Bureau of Mines), RI 289. Washington, DC: Department of Commerce, Bureau of mines; 1928.

19. Oliveira MILL, Chen K, Ferreira JMF. Influence of the deagglomeration procedure on aqueous dispersion, slip casting and sintering of Si3 N4 -based ceramics. J Eur Ceram Soc. 2002;22:1601-7.

20. Krell A, Blank P, Honggwei M, Hutzler T, van Bruggen MPB, Apetz R. Transparent sintered corundum with high hardness and strength. J Am Ceram Soc. 2003;86:12-8.

21. Krell A, Klimke J. Effects of the homogeneity of particle coordination on solid-state sintering of transparent alumina. $\mathrm{J} \mathrm{Am}$ Ceram Soc. 2006;89:1985-92.

22. Krell A, Klimke J, Hutzler T. Advanced spinel and sub- $\mu \mathrm{m}$ Al2O3for transparent armour applications. J Eur Ceram Soc. 2009;29:275-81.

23. Fu Q, Saiz E, Tomsia AP. Direct ink writing of highly porous and strong glass scaffolds for load-bearing bone defects repair and regeneration. Acta Biomater. 2011;7:3547-54.

24. Fu Q, Saiz E, Rahaman MN. Toward strong and tough glass and ceramic scaffolds for bone repair. Adv Funct Mater. 2013;23:5461-76.

25. Liu X, Rahaman MN, Fu Q. Bone regeneration in strong porous bioactive glass (13-93) scaffolds with an oriented microstructure implanted in rat calvarial defects. Acta Biomater. 2013;9:488998.

26. Nommeots-Nomm A, Lee PD, Jones JR. Direct ink writing of highly bioactive glasses. J Eur Ceram Soc. 2018;38:837-44.

27. Olhero SM, Fernandes HR, Marques CF, Silva G, Ferreira JMF. Additive manufacturing of $3 \mathrm{D}$ porous alkali-free bioactive glass scaffolds for healthcare applications. J Mater Sci. 2017;52:12079-88.

28. Eqtesadi S, Motealleh A, Miranda P, Lemos A, Rebelo A, Ferreira JMF. A simple recipe for direct writing complex 45S5 Bioglass ${ }^{\circledR}$ 3D scaffolds. Mater Lett. 2013;93:68-71.

29. Ben-Arfa BAE, Miranda Salvado IM, Ferreira JMF, Pullar RC. A hundred times faster: novel, rapid sol-gel synthesis of bio-glass nanopowders ( $\mathrm{Si}-\mathrm{Na}-\mathrm{Ca}-\mathrm{P}$ system, $\mathrm{Ca}: \mathrm{P}=1.67$ ) without aging. Int J Appl Glass Sci. 2017;8:337-43.

30. Ben-Arfa BAE, Fernandes HR, Miranda Salvado IM, Ferreira JMF, Pullar RC. Synthesis and bioactivity assessment of high silica content quaternary glasses with Ca: $\mathrm{P}$ ratios of 1.5 and 1.67, made by a rapid sol-gel process. J Biomed Mater Res A. 2018;106:510-20.

31. Ben-Arfa BAE, Salvado IMM, Ferreira JMF, Pullar RC. Enhanced bioactivity of a rapidly-dried sol-gel derived quaternary bioglass. Mater Sci Eng, C. 2018;91:36-43.

32. Ben-Arfa BAE, Fernandes HR, Salvado IMM, Ferreira JMF, Pullar RC. Effects of catalysts on polymerization and microstructure of sol-gel derived bioglasses. J Am Ceram Soc. 2018;101:2831-9.

33. He S, Qin Y, Walid E, Li L, Cui J, Ma Y. Effect of ball-milling on the physicochemical properties of maize starch. Biotechnol Rep. 2014;3:54-9.

34. Kazi SN, Badarudin A, Zubir MNM, Ming HN, Misran M, Sadeghinezhad E, et al. Investigation on the use of graphene oxide as novel surfactant to stabilize weakly charged graphene nanoplatelets. Nanoscale Res Lett. 2015;10:1-15.

35. Sun D, Kang S, Liu C, Lu Q, Cui L, Hu B. Effect of zeta potential and particle size on the stability of $\mathrm{SiO} 2$ nanospheres as carrier for ultrasound imaging contrast agents. Int J Electrochem Sci. 2016;11:8520-9.

36. Iller RK. The chemistry of silica solubility, polymerization, colloid and surface properties, and biochemistry. Toronto, ON: John Wiley \& Sons; 1978.

37. Larsson M, Hill A, Duffy J. Suspension stability: why particle size, zeta potential and rheology are important. Annu Trans Nord Rheol Soc. 2012;20:209-14.

38. Vinogradov J, Jackson MD. Zeta potential in intact natural sandstones at elevated temperatures. Geophys Res Lett. 2015;42:6287-94.

39. Liu X, Yu T, Wei Q, Yu Z, Xu X. Enhanced diamond nucleation on copper substrates by employing an electrostatic self-assembly seeding process with modified nanodiamond particles. Colloids Surf A Physicochem Eng Asp. 2012;412:82-9.

40. Lelievre F, Bernache-Assollant D, Chartier T. Influence of powder characteristics on the rheological behaviour of hydroxyapatite slurries. J Mater Sci Mater Med. 1996;7:489-94.

41. Vasconcellos SR, Kosman JJ, Rowell RL, Medalia AI. The relationship between zeta potential and particle size in non-aqueous carbon-black dispersions. J Dispers Sci Technol. 1983;4:409-13. 
42. Padilla S, García-Carrodeguas R, Vallet-Regí M. Hydroxyapatite suspensions as precursors of pieces obtained by gelcasting method. J Eur Ceram Soc. 2004;24:2223-32.

43. Huber T, Misra M, Mohanty AK. The effect of particle size on the rheological properties of polyamide 6/biochar composites. AIP Conf Proc. 2015;1664:150004.

44. Feilden E, Blanca EGT, Giuliani F, Saiz E, Vandeperre L. Robocasting of structural ceramic parts with hydrogel inks. J Eur Ceram Soc. 2016;36:2525-33.
How to cite this article: Ben-Arfa BAE, Neto AS, Miranda Salvado IM, Pullar RC, Ferreira JMF.

Robocasting: Prediction of ink printability in solgel bioactive glass. J Am Ceram Soc. 2019;102:16081618. https://doi.org/10.1111/jace. 16092 